\title{
Formação do Psicólogo: Um Debate a Partir do Significado do Fenômeno Psicológico
}

\begin{abstract}
A Psicologia é apresentada despida de suas pendências naturalizantes. O ser humano é visto como aquele que cria a história ao invés de sofrê-la passivamente. $\mathrm{O}$ artigo recoloca, seriamente, a Psicologia como participante do elenco das ciências sociais.
\end{abstract}

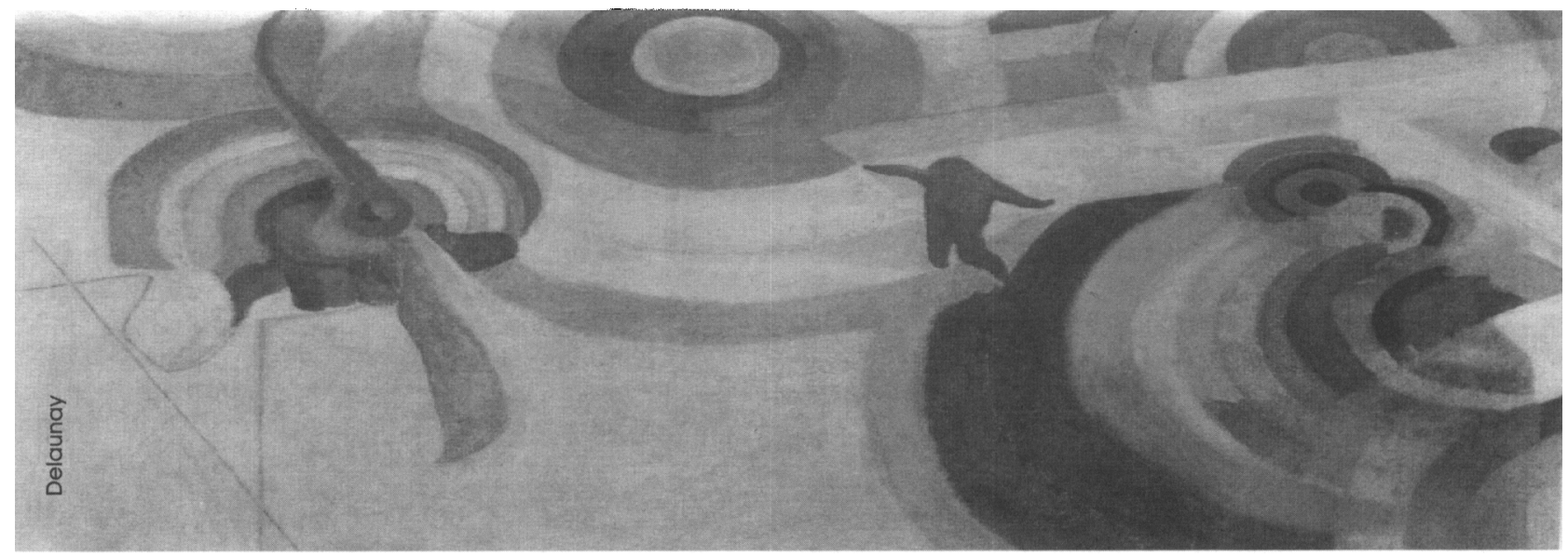

Vários estudos têm sido apresentados sobre a formação do psicológico. Pretendemos aqui, acrescentar a essa discussão um aspecto pouco abordado: a visāo sobre o fenômeno psicológico e sobre o homem que tem embasado nossas propostas de formação.

É importante explicitar algumas referências teórica básicas que guiam nossa reflexão e que guiam aqui nossa visão sobre a formação: a concepção sócio-histórica em Psicologia, que, resumidamente, está fundada em cinco pontos básicos:

1. Não existe a natureza humana: o homem tem sido pensado, na Filosofia e em várias ciências, a partir da idéia de Natureza Humana concebida como uma essência universal e abstrata, o que o caracteriza desde sua origem. É a forma humana do Absoluto. Nestas concepçōes há sempre um homem apriorístico dentro do homem; há um homem que se atualizará, que se realizará, se as condiçōes adequadas forem dadas. Há uma natureza em cada homem, natureza esta que o faz homem e que determina suas possibilidades.

Para nós, essa idéia de natureza humana tem um caráter ideológico, pois camufla a determinaçāo social do homem, pensando-o de forma descolada de sua realidade social, realidade essa que o constitui e lhe dá sentido.

O homem e todo pensamento teórico e sistemátıco sobre ele tem origem na realidade sociał. No entanto, o resultado que temos nas ciências é uma idéia de homem como autônomo, como uma entidade, dotado de uma essência que o caracteriza como homem. A realidade social passa a ser pensada como o local onde essa essência se desenvolve, atualiza-se, dasabrocha e realiza-se. Toda a determinação social do homem fica oculta sob essas idéias e conceitos, que se tornam representaçōes ilusórias.

2. Existe a condição humana: A condição humana estaria dada por dois elementos: o homem constról as formas de satisfação de suas necessidades e faz isso com os outros homens.

A idéia de condição humana é fundamental para darmos o salto da concepção naturalista do homem para uma concepção sócio-histórica.

Na idéia de condição humana, nada no homem está aprioristicamente concebido. Não há nada em termos de habilidade, faculdade, valores, aptidōes ou tendências que nasçam com o ser humano. As condições biológicas hereditárias do homem são a sustentação de um desenvolvimento sócio-histórico, que the imprimirá possibilidades, habilidades, valores, aptidōes e tendências historicamente conquistadas pela humanidade e que se encontram
Ana Mercês Bahia Bock

Doutora em Psicologio Social

Diretora da Faculdade de Psicologia da PUC/SP

Presidente do Conselho

Federal de Psicologia 
condensadas nas formas culturals desenvolvidas pelos homens em sociedade.

3. O homem é um ser ativo, social e histórico: 0 homem produz sua sobrevivência com os outros homens. A relaçào do homem com a natureza, através de suas atividades, e a relação com os outros homens constituem o ser humano. Como essa atividade sobre o mundo é um processo histórico, pois os homens vão construlndo novas formas de satisfação de suas necessidades e vão também construindo novas necessidades, há um permanente movimento e um permanente processar do homem.

4. O homem é criado pelo homem: Nāo há natureza humana pronta. Não há aptidões. A única aptidão do homem é poder desenvolver várias aptidōes. $\mathrm{E} O$ desenvolvimento do indivíduo se dá através do contato com a cultura e com os outros homens. Os objetos da cultura materializam a história e cristalizam as aptıdões desenvolvidas pela humanidade no decorrer de sua história. $\mathbf{O}$ indivíduo, ao entra em contato com esses objetos, "descongela" essas aptidões e adquire as habilidades necessárias a sua sobrevivência na cultura humana. O homem se constitul e aprende a ser homem.

$O$ individuo, ao adquirir as condiçōes para sobreviver, adquire também uma visāo de pois essa relaçāo do homem com a cultura, mediada que está pelos outros homens, tem como elemento mediador fundamental a linguagem. No conjunto das relaçōes soclals, mediadas pela linguagem, o Individuo val desenvolvendo sua consciência. Com 0 desenvolvimento da consciência, o homem sabe seu mundo, sabe-se no mundo, antecede as coisas do seu mundo, partilha-as com os outros, troca, constról e reproduz significados. Quando atua sobre o mundo, relacionando-se, apropria-se da cultura e adquire linguagem; apropria-se dos significados e constrói um sentido pessoal para suas vivências. Tem, assim, todas as condicōes para atuar com os outros, criar cultura e elaborar significados. O homem, se faz homem ao mesmo tempo que constrói seu mundo.

5. O homem concreto é objeto da Psicologla: A Psicologia deve buscar compreender 0 individuo a partir da inserção desse homem na sociedade. $O$ indivíduo só pode ser realmente compreendido em sua singularidade, quando inserido na totalidade soclal e histórica que 0 determina e dá sentido a sua singularidade.

A Psicologia não tem trabalhado Baräo de Münchhausen na Psicologia: um estudo sobre o significado do fenômeno psicologico na categoria dos psicólogos - tese de doutoramento em Psicologia Social PUCSP/97 totalidade que o determina, estudando-o de forma isolada. Com esse procedimento, a Psicologla tem naturalizado o homem e 0 mundo, adquire um conjunto de significados,

aparece apenas como "canteiro", onde a semente de homem, com sua natureza psíquica, pode se desenvolver. As condições materiais de vida não sāo tomadas, pela Psicologia, como constitutivas do psiquismo.

Com base nestas concepcōes e considerando as determinações já apontadas acima, pretendemos refletir criticamente sobre as concepçōes de homem e de fenômeno psicológico que têm fundamentado a prática dos psicólogos e a formaçāo. Vale ressaltar que estas reflexōes estão sistematizadas em trabalho de pesquisa realizado como doutoramento'.

O fenômeno psicológlco tem sido visto de forma abstrata. Ora como manifestação de processos internos, ora como produto de vivências externas, ora como conteúdo do mundo interno, ora como processo, mas sempre visto de forma abstrata e naturalizante. O fenômeno é visto como algo da espécie humana, característica universal da espécie e aparece definido por um número enorme de palavras e expressões, como por exemplo: manifestaçōes do aparelho psíquico, Individualidade, subjetividade, mundo interno, manifestacōes do homem, pensar e sentir o mundo, consciência, inconsciente, vivênclas, engrenagens de emoções, motivações, comportamentos, habilldades e potencialidades, experiências emocionais, conflitos pulsionals, psique, pensamento, sensaçōes, entendimento de si e do mundo, manifestaçōes da vida mental, tudo que é percebido pelos sentidos.

Há pouco consenso sobre o fenômeno psicológico entre os psicólogos, mas alguns elementos aparecem na maior parte das concepçōes: um fenômeno interior ao homem, que possui vários componentes e recebe influências do meio físico e social em seu desenvolvimento. A interação com o ineio é portanto fator de desenvolvímento. Há nele algo de biológico e algo de social; algo de consciente e algo de inconsclente. É um fenômeno que se desestrutura, se desequilibra, se desorganiza e o psicólogo parece ter os instrumentos adequados para lidar com ele.

Esta visāo do fenômeno psícológico, o pensa como algo descolado, independente do indivíduo. Ele está transformado, no discurso dos psicólogos, em uma entidade que atormenta, restringe, possibilita, enriquece, movimenta-se, desenvolve-se; uma entidade que tem vocação, destino, percurso, uma realização a cumprir. Mecanismos unlversais caracterlzam, assim, esse fenômeno.

A Idéla da existência de um meio está psiquismo acaba sendo tomado como algo já existente no homem, que se realiza, desabrocha, atualiza-se; o psiquismo é tomado como um a prior no homem. A realidade soclal presente, mas é um meio genérico, que às vezes é social e às vezes é físico. Esse meio Influencia o indivíduo, mas essa influência também é genérica. Recheia, preenche, molda, constitui, possibilita, impede, bloqueia, 
molda, constitul, possibilita, Impede, bloquela, estimula.

Há, a nosso ver, uma questāo de fundo nestas concepções: a visão de homem que as fundamenta. O Homem não está conceltuado a partir de uma perspectiva histórica. Não é pensado como alguém que se constitul ao constitulr o seu mundo. É pensado separado das condiçōes de vida. É pensado a partir de uma perspectiva de natureza humana isto é, um ser dotado de uma essência universal e abstrata, que faz dele homem.

o homem aparece como um ser que possul em si a essêncla humana e seu desenvolvimento nada mals é do que a atualizaçāo desta essência. Há um homem apriorístico em cada um de nós. Além disso, a noção de homem carrega uma visão de que é um ser dotado de possibilidades de controlar, garantir, responsabilizar-se pelo seu próprio processo de individualizaçāo.

Um aspecto que chama a atenção na visão de homem é a existência de um "eu verdadeiro" que habita o indivíduo; um eu cheio de potencialidades, de habilidades, que com certeza estão referenciadas na idéla de natureza humana, e que não se manifestam de imediato. Esse "eu" deverá, no decorrer da vida, dependendo das experiências vividas, realizarse, presentificar-se, atualizar-se. As condiçōes sociais são aqui impeditivas dessa tarefa.

A relação do Indivíduo com a socledade é uma relação praticamente inexistente. As relaçōes apontadas como necessárias e Importantes para o desenvolvimento do homem dizem respeito, fundamentalmente, às relaçōes com os outros homens. Nāo são, no entanto, relaçōes situadas no tempo histórico, em condições determinadas de vida, permeadas de signnificaçōes e linguagens específicas, com condlções de trabalho e formas de produção da sobrevivência. Nāo há a visão de um conjunto de homens compartilhando esses elementos históricos e sendo determinados por esses elementos. O termo social parece se referir apenas'à existência de outros homens.

A prática profissional, conseqüência destas concepçōes, é vista como uma prática técnica, isto é, uma prática que contém um saber (métodos, técnicas e teorias) que auxilia o desenvolvimento do homem. Auxilla a retomada de um "caminho desviado", auxillam a reduçāo do sofrimento, o autoconhecimento necessário para o equilíbrio e a adaptação ao meio social. O trabalho busca esclarecer, permltir a compreensão, favorecer a escuta, conhecimento de aspectos desconhecidos, explicitar aspectos do Individuo que ele desconhece etc. Nāo se coloca uma finalidade social ou política para essa prática. As finalidades estāo ligadas apenas ao indivíduo e a um movimento que lhe é próprio, natural, que deve ser conservado ou reconduzido.

A prática aparece também associada à Idéla de ajuda ao próximo, de auxílio, de compreensão absoluta, de aceitação total.

Ajuda ao outro, finalidade de adaptaçāo, busca de felicidade e do equilíbrio evidenclam uma noção onipotente da profissào. O psicólogo parece ter em suas mãos a possibilidade de fazer do outro um homem fellz, colocá-lo em movimento, estimulá-lo, acompanhar seu destino, converter percepçōes em consciência, estruturar, transformar, humanizar, enfim, acredita que muito pode ser feito e muitas mudanças podem ser operadas com a ajuda do psicólogo, enquanto portador de um conhecimento e enquanto ser humano dotado de intuição.

No entanto, encontramos, contradi torlamente, o discurso: o psicólogo nāo muda o homem, apenas contribui para que ele próprio se modifique. $E$ a onipotência se traveste de humildade absoluta e o psicólogo nega seu próprio trabalho. Nega a sua intervenção como um trabalho, isto é, como uma intervençāo dirigida para uma finalidade na qual emprega sua energia para transformar o que se apresenta naquilo que surge em seu pensamento como o fim desejado.

Outro aspecto importante de considerarmos nesta reflexão, é a noção de saúde, pols tem sido definidora da identidade dos psicólogos. Saúde é um conceito que complementa e reforça todas as outras concepçōes. É definida a partir de conteúdos morais que, em última instância, nos ajudam a compreender a essência universal e eterna atribuida ao homem. Aparecem, então, como critérios de saúde: autoconfiança, abertura para as experiências, juízo crítico, espírito contestário, conhecimento de como usufruir os momentos da vida, de como compartilhar com seus semelhantes, simpatia, solidariedade, compreensāo do que é amar, trabalhar e brincar, vivênclas de relaçōes afetivas, interação harmoniosa com o meio, expressão de emoçōes, afetividade e Inteligência, buscas, movimentos constantes, doação, sustentação de sua próprla fala, contribuição a favor da vida, sentimento de utilidade, promoção de seu crescimento pessoal, autônomo para ser feliz, exercício da cidadania, equilíbrio, adaptaçāo, ajustamento ao meio.

A definição de saúde expressa visōes adaptativas, trazendo capacidades que os homens devem possuir para estar bem; visōes naturalizantes, trazendo um desenvolvimento previsto, esperado, natural do homem; visōes médicas, trazendo estados ideais para o homem sentir-se bem e visões abstratas, que trazem condiçōes adequadas para se ter saúde. Em nenhuma dessas concepçōes se faz

\author{
A relação do \\ indivíduo com a \\ sociedade é uma \\ relação \\ praticamente \\ inexistente. As \\ relações apontadas \\ como necessárias e \\ importantes para 0 \\ desenvolvimento do \\ homem dizem \\ respeito, \\ fundamentalmente, \\ às relaçōes com os \\ outros homens.
}


a relação com as condiçōes de vida a que os homens estão submetidos. pelo contrário, a maioria delas carrega a noçāo de que a saúde depende de esforço próprio do homem. O meio, quando aparece relacionado, surge como terreno "onde cai a sementinha de homem" e que pode ser um terreno fértil ou nāo.

Todo esse conjunto de elementos na visāo do fenômeno psicológico, da visão de homem e de saúde não foi, no entanto, inventado na e pela Psicologia. Estas concepçōes tem seu fundamento na visão liberal dominante, que possui como valor central $o$ individualismo.

O liberalismo, expressão necessária

Todo esse conjunto de elementos na visão do fenômeno psicológico, da visão de homem e de saúde não foi, no entanto, inventado na e pela Psicologia. Estas concepções tem seu

fundamento na visão liberal dominante, que possui como valor central o individualismo. do modo de produção capitalista está fundamentado na idéia de que cada indivíduo é um ser moral que possui direitos inalienáveis, derivados de sua própria humanidade. Dotado de potencialidades, deve ser livre para desenvolvê-las. A submissão dos indivíduos a condiçōes opressivas de vida e a vontade arbitrárias é incompatível com a dignidade humana e com a idéia de autonomia do ser humano. Para resolver essa difícil questão da liberdade dos indivíduos, o liberalismo colocou na Lei a expressāo daquilo que garante a liberdade de cada um, criando, assim, algo acima de todos, impessoal e objetivo, que garante o controle das vontades individuais $e$, conseqüentemente a liberdade necessária ao desenvolvimento de cada um.

As teses fundamentais do liberalismo clássico são, portanto, os direitos naturais à liberdade e à igualdade e os direitos legais de propriedade e segurança.

o liberalismo se desenvolveu em nossa sociedade. $O$ positivismo fertilizou o liberalismo com seus conceitos abstratos e universais de neutralidade, objetividade, progresso, ordem e desenvolvimento, coesão e moral. Esse liberalismo incrementado fol fundamental para a construção de uma sociologia da ordem, na qual se neutralizaram as contradiçōes existentes na sociedade de classes e despolitizaram suas manifestações. $O$ positivismo ainda rechaçou o indivíduo como categoria de pensamento, entregando-o aos cuidados da psicologia do ajustamento e da adaptaçāo, que o estudou de forma isolada das condiçōes materlais da sociedade.

$O$ individualismo, valor central da ideologia liberal, expressa um pensamento sobre o homem, onde este não é concebido como ser social, mas sim como possuidor de direitos naturais e de propriedades universais. Os indivíduos possuem características $\mathrm{e}$ atributos que se configuram de modo particular, determinando seu lugar social, seu sucesso ou fracasso na sociedade. Dadas condiçōes adequadas e liberdade aos condiçōes adequadas e liberdade aos indivíduos, estes são os únicos responsáveis pelo seu desenvolvimento.

A Psicologia trabalhou sob a orientaçāo liberal e positivista, produzindo uma naturalização do homem, isto é, o concebeu a partir da noçāo de natureza humana; um homem apriorístico, que tem seu desenvolvimento previsto pela sua própria condição de homem. Este desenvolvimento pode ser facilitado ou dificultado pelo melo externo, social e cultural. Um homem livre, dotado de potencialidades, responsável pelo seu processo pessoal. O homem foi afastado da realidade social e o fenômeno psicológico tornou-se uma entidade abstrata. O fenômeno psicológico é algo que o homem já possui aprioristicamente, pois pertence à natureza humana. É algo privado e íntimo. É a essência do homem. E no decorrer do tempo histórico foi se desenvolvendo o sentimento de identidade individual e conhecer-se a si mesmo tornou-se uma finalidade. A psique passou a ser tratada como se tivesse uma vida interior própria, devendo ser cuidada e conhecida. A Psicologia teve, entāo, um grande desenvolvimento e importância na sociedade moderna.

Importante, neste momento de nossa reflexāo, registrar que outras visões de homem e de fenômeno psicológico, foram produzidas no decorrer da história da Psicologia. No Brasil, desde Manoel Bomfim, Ulisses Pernambucano e outros, se buscou uma concepção alternativa à dominante. Hoje, encontramos, com freqüência, nos debates entre psicólogos, a colocação de questões que põem em dúvida as "verdades" do liberalismo. Vale registrar que as mudanças sociais vividas em nossa sociedade nas décadas de 70 e 80 , colocaram novas possibilidades teóricas para os psicólogos, que tínham em suas práticas, nos setores públicos de serviço à população, desafios enormes, poís sentiam a necessidade de rever seus conhecimentos, obtidos nos cursos de Psicologia, para poder efetivamente prestar o serviço. Estes desafios foram de enorme importância para que em alguns espaços da Psicologia se desencadeasse um processo de crítica e de revisão do seu compromisso e dos seus conhecimentos.

Idéias e teorias psicológicas críticas, inovadoras e conspiradoras convivendo com uma Psicologia, essa dominante em nosso meio profissional, carregada de concepçōes liberais, que transforma em entidades as realidades que apreende. Uma Psicologia que tem transformado todos os problemas que são sociais, em problemas individuais; que tem reduzido o homem, como ser social que se constitul nas relaçōes e nas atividades, a um homem isolado, dotado de potencialidades $\mathrm{e}$ natureza humana, como essência universal e genérica. Uma Psicologia que ignora a 
realidade política e social das desigualdades. Uma Psicologia que contribui para o ocultamento da realidade social, na medida em que acredita que esta só pode ser compreendida a partir da realidade Individual. Uma Psicologia que enquanto profissão possul uma tônica individualista, voltada para o patológico $e$ calcada na crenca de que o indivíduo possui possibilidades de sozinho responsabilizar-se pelo seu processo de individualização.O esforço do autoconhecimento, esforço este que elimina aspectos exteriores que dificultam ou impedem o desenvolvimento pleno de potencialidades naturais. Um homem que, com a ajuda da Psicologia, descobre e conhece seu "verdadeiro eu" (outro mito da Psicologia Liberal!), tornando forte para enfrentar a realidade, que por natureza é algo que se opõe aos interesses e possibilidades naturais do desenvolvimento humano. Um homem em choque com a realidade social. Um homem dividido em dois: um que é ele mesmo e outro que é o estranho. Um que é natural e outro que é social.

Toda essa reflexão para podermos pensar a formação nessa nova perspectiva. A formação dos psicólogos tem sido dominada pela visão liberal de homem. Temos formado nossos psicólogos na perspectiva do individualismo, da naturalização do homem e do fenômeno psíquico. Temos priorizado a prática clínica nos consultórios particulares (nossas clínicas escola têm se constituído à imagem e semelhança destes consultórios e não à imagem e semelhança das instituiçōes do servico público). Temos atraído jovens que desejam "fazer Psicologia" para ajudar o outroe conhecer-se a si próprio ${ }^{2}$, denotando valores individualistas em uma prática assistencial. Não temos conseguido mudar esses motivos de escolha da profissão, temos apenas, como demonstrou Mello ${ }^{3}$, aperfeiçoado o discurso de nossos alunos, sem alterar os valores subjacentes. Temos fornecido uma formação técnica que ensina a atuar de determinada maneira em determinada situação, desenvolvendo pouco ou quase nada a capacidade de lidar com o novo, com o desconhecido.

Várias análises têm apontado que o psicólogo aprende pouco sobre o que seja o fenômeno psicológico com o qual trabalha, tornando-se difícil a construção de novos fazeres. Carvalho ${ }^{4}$ analisa esta questão em muitos de seus estudos e nossa pesquisa pode reforçar essa conclusão, mostrando que os psicólogos não têm um discurso único ou parecido para designar o fenômeno psicológico, mas subjacente às diversas definiçōes está uma visão libberal e individualista de homem e do fenômeno psicológico. Essa nossa conclusão nos permite avançar afirmando que não basta trabalharmos na construção de um psicológico. Essa nossa conclusão nos permite avançar afirmando que não basta trabalharmos na construção de um consenso sobre o fenômeno, mas é preciso trabalhar na construção de uma concepçāo social do psiquismo humano.

Essa concepção social do psiquismo deverá contribuir para que nossa prática e nossas análises da realidade humana possam ser "desvendadoras" das condicōes sociais. Estaremos trabalhando para construir uma Psicologia política que, ao fazer seu trabalho, denuncia condições desumanas de vida, denuncia desigualdades, que até agora foram acobertadas por conceltos psicológicos como diferenças individuals, potencialidades, autonomia e outros.

Nessa formação, o ensino das técnicas deve ser entendido como elemento da praxis. As técnicas não podem ser ensinadas como elementos fechados em si mesmos, mas como instrumentos a serviço de uma finalidade.

0 ensino da pesquisa deve ter lugar de destaque, construindo uma postura, nos profissionais, de permanente curiosidade, crítica, insatisfação e busca do novo. A certeza de que o conhecimento é histórico e deve acompanhar o movimento da realidade.

Um psicólogo em movimento. Essa deve ser a nossa meta. Um psicólogo aliado da transformação social, do movimento da sociedade e dos interesses da maioria da população. Um psicólogo inquieto, conspirador, que saiba estranhar aquilo que na realidade se torna tão familiar que chega a ser pensado como natural. Um psicólogo em permanente metamorfoses. Um psicólogo permeável às inovaçōes que aceite o desafio de, coletivamente, produzir alternativas à Psicologia tradicional.

\section{É possível esta formação?}

Acredito que sim.

Não acho que seja fácil ou simples, mas acho que possível. Cabe aos professores e às entidades da categoria a construçāo do espaço para essa organização e construção do novo projeto.

Gostaria de terminar sistematizando alguns elementos da formação crítica que estamos aqui defendendo:

1. É preciso uma formação plural, isto é, as mais diversas teorlas em Psicologia devem estar sendo ensinadas. No entanto, essa formação pluralista deve estar acompanhada de uma formação sólida que ensine a perspectiva filosófica e epistemológica que embasa cada teoria. Qual é a visão de homem e qual a visão de produção de conhecimento que estão embasando essas visōes teóricas.

Allada a essa discussão, deve-se compreender a visão de fenômeno psicológico
${ }^{2}$ Ver Conselho Federal de Psicologia- Quem é o Psicologo Brasileiro-Edicon/ EDUC/ Scientia er Labor, 1988, SP

'Mello, S.L. - Psicologia e Profissáo em Säo Paulo Ed.Ática, São Paulo, 1975

'Carvalho, A.M.A.- Atuação Psicológica: alguns elementos para uma reflexäo sobre os rumos da profissão e da formação, em Conselho Federal de Psicologia -Revista Psicologia Ciência e Profissão. ano 4 , número 21 $1984, p .7 / 9$

${ }^{5}$ conceito trabalhado por Ciampa, A.C. a partir de seu livro: $A$ estória do Severino e a história da Severina- um ensaio em Psicologia Social,

Ed.Brasiliense,

Sāo Paulo, 1982 
Um psicólogo em movimento. Essa deve ser a nossa meta. Um psicólogo aliado do transformação social, do movimento da sociedade e dos interesses da maioria da população.

\section{Referências} bibliográficas de cada teoria ensinada. Não é possível se falar do fenômeno, se ensinar a lidar com ele e mesmo a transformá-lo, sem que se explicite sua concepção. Esta formação abstrata que temos propiclado precisa ser superada.

2. É preciso uma formação que estimule o aluno à pesquisa. Uma formação que ensine a perguntar, a estranhar o familiar $e$ buscar novas respostas. $O$ conhecimento deve ser ensinado como histórico, isto é, como um saber produzido para responder a determinadas questōes em um determinado momento da sociedade, por isso um saber em permanente movimento.

3. É preciso uma formação que ensine a construir projetos a partir de situaçōes desafiadoras e novas. $\dot{E}$ preciso formar psicólogos criativos no sentido de profissionais que sabem, frente a uma nova realidade, recorrer criativamente ao seu saber.

4. É preciso uma formação em Psicologia colada à realidade social brasileira. Uma formação Impregnada de realidade. Uma formação que, ao ensinar as teorias e saberes acumulados, é capaz de falar da realidade vivida pela população brasileira. Uma formação que permita a entrada franca da realidade cotidiana. Uma formação que integre numa leitura ampla as várias dimensōes desta realidade.

5. É preciso uma formação que ensine técnicas de intervenção como instrumentos a serviço de finalidades amplas. $O$ instrumento deve ser ensinado como elemento da praxis $\mathrm{e}$ não como um elemento fechado em si mesmo. Os instrumentos têm finalidades; os instrumentos estāo a serviço de concepçōes e valores. Devem ser ensinados de forma crítica, isto é, desvendando essas relações.
6. É preciso uma formaçāo interdisciplinar em dois sentidos: primeiro que contemple várias áreas da ciências, fornecendo conhecimentos que possam enriquecer o conhecimento da Psicologia. Segundo, uma formação que prepare o profissional para o trabalho coletivo $\mathrm{e}$ parceiro com outros profissionais.

7. É preciso uma formação cuidadosa $e$ rica em Psicologia. Várias teorias, várias técnicas, pesquisas. Só uma formaçāo densa, cuidadosa e diversa poderá ser fundamento da habilidade de perguntar. Queremos um psicólogo que faça perguntas à realidade.

8. É preciso uma formação generalista, com um pequeno grau de especialização apenas no último ano. Os estudantes de Psicologia devem compreender que $o$ aprendizado da Psicologia implica o conhecimento de todas as suas possibilidades e contribuiçōes. Devem ser formados para serem psicólogos capazes de utilizar o conhecimento especifico da Psicologia para intervençōes que se fizerem necessárias.

9. É preciso uma formação cuidadosa, diversa, instigante no treino da prática profissional. Nossos estágios deverão ser revistos, buscando novos campos, novas instituiçōes, novas orientaçōes.

10. E preciso uma formação de um profissional comprometido com o seu tempo e sua sociedade, que trabalhe na promocaao de saúde desta comunidade. Um profissional que discuta seu compromisso com a sociedade, um profissional que retire deste debate a finalidade social de seu trabalho; um profissional cidadão.
Bock, A.M.B., Gonçalves, M.G.M et alli-A Psicologia SócioHistórica-mimeo, São Paulo, 1996

Carvalho, A.M.A. -Atuação Psicológica-alguns elementos para uma reflexão sobre os rumos da profissão $e$ da formação - in Conselho Federal de Psicologia- Revista Psicologia: Ciência e Profissão, ano 4, no.2/ 1984, p.7/9

Charlot, B. -A Mistificação Pedagógica: realidades sociais e processos ideológicos na teoria da educação -Zahar Ed.,RJ, 1979

Comissão de Especialistas de Ensino de Psicologia MEC/SESU- $A$ Formação em Psicologia: contribuiçōes para reestruturação curricular e avaliação dos cursos, mimeo,
Conselho Federal de Psicologia (Câmara de Educação e Formação Profissional) - Psicólogo Brasileiro - práticas emergentes $e$ desafios para a formação - Ed.Casa do Psicólogo, SP, 1994

Mello, S.L. - Psicologia e Profissão em São Paulo - Ed.Ática, SP, 1975

Warde, M.J. - Liberalismo e Educação - tese de doutoramento, PUC-SP, 1984 